\title{
Atitudes Linguísticas no Falar dos Costarriquenses
}

\author{
Actitudes Linguísticas en el Habla de los Costarriquenses
}

Linguistic Attitudes in Costa Rica Speadking

\author{
Antonio Carlos Santana de Souza ${ }^{1}$ \\ Wanessa Rodovalho Melo Oliveira ${ }^{2}$
}

\begin{abstract}
Resumo
Este estudo propõe discutir sobre as atitudes linguísticas presentes na fala dos nativos do município de Costa RicaMS, sendo este o lócus desta pesquisa por pertencer à Tríplice Fronteira entre os estados de MS, MT e GO. Nesse sentido, alguns objetivos específicos permearam o tema em questão, a fim de compreender como os costarriquenses percebem a própria língua; analisar como os falantes nativos desta cidade veem a fala e as influências dos imigrantes; identificar, a partir da perspectiva da Sociolinguística, o sotaque dos costarriquenses. Portanto, a proposta deste trabalho pauta-se na abordagem quali-quantitativa, a partir da aplicação de um questionário semiestruturado com 13 perguntas dirigidas a 20 costarriquenses entrevistados por meio do aplicativo WhatsApp em virtude da pandemia mundial causada pelo Covid 19. A pesquisa constatou-se que os costarriquenses entendem a língua que falam como a de prestígio, contudo, ressalta-se que existem diferentes falares na região, sobretudo entre os próprios nativos. Não obstante, os dados da pesquisa também revelaram que a fala que consideram como a mais correta não é a deles, pois classificam-na como caipira, tendo o $r$ e $s$ puxados, que, segundo eles, isto se deve às suas raízes e às influências dos imigrantes, principalmente dos goianos e mineiros.
\end{abstract}

Palavras-chave: Atitudes linguísticas. Costarriquenses. Os falares.

\section{Resumen}

Este estudio propone discutir las actitudes lingüísticas presentes en el habla de los nativos del municipio de Costa Rica-MS, siendo este el lugar de esta investigación por pertenecer a la Triple Frontera entre los estados de MS, MT y GO. En este sentido, algunos objetivos específicos impregnaron el tema en cuestión, siendo comprender cómo los costarriquenses perciben su propia lengua; analizar cómo los hablantes nativos de esta ciudad ven la habla y las influencias de los inmigrantes; identificar, desde la perspectiva de la Sociolingüística, el acento costarriquense. Por tanto, la propuesta de este trabajo se fundamenta en el abordaje cualitativo y cuantitativo, el cual, a partir de la aplicación de un cuestionario semiestructurado con 13 preguntas dirigidas a 20 costarriquenses entrevistados a través de la aplicación WhatsApp debido a la pandemia mundial provocada por la Covid 19, se encontró que los costarriquenses entienden el idioma que hablan como un idioma de prestigio, pero, cabe señalar que existen diferentes acentos en la región, especialmente entre los propios nativos. Sin embargo, los datos de la investigación también revelaron que la habla que consideran más correcto no es el suyo, ya que lo clasifican como pueblerino, teniendo la " $\mathrm{r}$ " y la "s" destacadas, lo que, según ellos, se debe a sus raíces y a las influencias de los inmigrantes, principalmente de Goiás y Minas Gerais.

Palabras clave: Actitudes lingüísticas. Costa Rica. Hablar.

\begin{abstract}
This study proposes to discuss the linguistic attitudes present in the speech of the natives of the municipality of Costa Rica - MS, this being the locus of this research for belonging to the Triple Border between the states of MS, MT and GO. In this sense, some specific objectives permeated the theme in question, being to understand how
\end{abstract}

1 Pós Doutor em Linguística pela UFMT/PNPD-CAPES (2018/2019). Pós Doutor em Linguística pela UNEMAT (2016). Doutor em Letras pela UFGRS. Docente Permanente do Programa de Pós-graduação (Mestrado/Doutorado) em Linguística da UNEMAT/Cáceres. E-mail: acssuems@gmail.com

2 Mestra em Letras pela Universidade Estadual de Mato Grosso do Sul (UEMS). E-mail: wanessarmelo@hotmail.com 
Costa Ricans perceive their own language; analyze how native speakers of this city see the speech and influences of immigrants; to identify, from the perspective of Sociolinguistics, the Costa Rican accent. Therefore, the purpose of this work is based on the qualitative and quantitative approach, which, through the application of a semistructured questionnaire with 13 questions addressed to the 20 Costa Rican interviewed through the WhatsApp application due to the global pandemic caused by Covid 19, was found that Costa Ricans understand the language they speak as a language of prestige, however, it is emphasized that there are different languages in the region, especially among the natives themselves. Nevertheless, the research data also revealed that the speech they consider to be the most correct is not theirs, as they classify it as a hillbilly, with strong ears, which according to them, this is due to their roots and the influences of immigrants mainly from Goiás and Minas Gerais.

Keywords: Linguistic attitudes. Costa Rican. Speak.

\section{Introdução}

Muitos são os falares presentes em todo território brasileiro, cada região possui suas particularidades e as evidencia em seus sotaques e costumes, de modo que a cultura se manifesta nas diversas modalidades regionais, sociais, históricas e outras que envolvem o falante brasileiro. Com esta pluralidade nos falares, os conceitos de prestígio e preconceito linguístico estão diretamente relacionados à posição social do falante, ao contexto em que ele está inserido e também ao nível de escolaridade e cultura, em que cada um possui a sua própria visão acerca da língua que fala e da que ouve. Esses fatores fazem com que as pessoas sejam julgadas pelo seu modo de falar e por suas atitudes e crenças linguísticas, que, na realidade, são julgamentos que fazem sobre a identidade construída, o que remete ao desprestígio, porque a língua portuguesa não está relacionada apenas à norma culta, mas às distintas variedades de sua realização, à forma como o falante a representa.

Partindo desse ponto, esta pesquisa visa conhecer as atitudes linguísticas que constroem a identidade deste povo, além de saber como os costarriquenses veem a própria língua e a dos imigrantes locais, assim como as influências geradas até os dias atuais, no sentido de observar se elas são avaliadas de maneira prestigiosa ou não, de modo a identificar qual é o sotaque dos costarriquenses.

O lócus da pesquisa é o município de Costa Rica, localizado ao Nordeste do Estado de Mato Grosso do Sul, fazendo fronteira com os Estados de Mato Grosso e Goiás, e tem como distrito Baús, que serviu de abastecimento na guerra do Paraguai.

O corpus foi construído a partir de um questionário norteado pelos fundamentos de Manzini, a partir da abordagem de três categorias de pesquisa: “a) questões relacionadas ao planejamento da coleta de informações; b) questões sobre variáveis que afetam os dados de coleta e futura análise; c) questões que se referem ao tratamento e análise de informações advindas de entrevistas" (Manzini, 2003, p. 11), o que corrobora a pesquisa Sociolinguística consolidada por Labov (2008), cujo maior aspecto é a pesquisa Quantitativa. Além disso, a 
análise livre dos pesquisadores foi priorizada para atender ao aspecto da pesquisa Qualitativa. Aspectos que envolvem as atitudes linguísticas são estudados e discutidos por psicólogos sociais como Lambert e Lambert (1972) cujas análises psicológicas apontam como o falante se sente e se reage diante dos outros. Outrossim, variadas pesquisas brasileiras têm discutido o tema.

No estudo em questão, as análises mostram que a fala presente no município de Costa Rica é de prestígio, pois os costarriquenses possuem orgulho do seu sotaque, assim como veem as influências recebidas pela cultura dos imigrantes de maneira positiva. Alguns deles conseguem descrever o seu sotaque como Caipira, ou, ainda, consideram a pronúncia do "r" como puxado. Embora os falares deles estejam propensos a mudanças, eles acreditam que isso só tem a beneficiar o município, logo parecem não demonstrar preocupação em perder a identidade linguística, uma vez que as gerações mais novas não falam da mesma maneira que os mais velhos, apesar de ainda possuírem algumas semelhanças.

\section{As atitudes linguísticas: conceito e abrangência}

As atitudes linguísticas estão relacionadas à identidade do falante, já que o modo como a pessoa fala revela suas preferências e vivências, leva a julgamentos sobre a forma como falam, com sotaques e dialetos, mas também sobre o conteúdo do que se fala, como aponta Calvet: “[...] as pessoas serão julgadas segundo o seu modo de falar" (CALVET, 2002, p. 69). Tarallo defini as atitudes linguísticas como as “[...] diversas maneiras de se dizer a mesma coisa em um mesmo contexto e com o mesmo valor" (TARALLO, 1986, p. 8). Portanto, as atitudes linguísticas têm em sua função compreender o fenômeno da variação de modo que este revele a função da língua e suas variantes no contexto do falante.

As primeiras pesquisas que envolviam as atitudes linguísticas foram realizadas pelos psicólogos sociais Lambert e Lambert em seus estudos sobre o bilinguismo francês-inglês, contexto em que gravações eram disponibilizadas a diferentes grupos para perceberem as opiniões deles sobre a língua exposta, particularmente julgamentos de como as pessoas seriam em seu aspecto físico, profissional, intelectual e prestígio social. Após as análises, os ouvintes não perceberam que as gravações foram feitas por uma mesma pessoa bilíngue. Conclui-se, portanto, que " $[\ldots]$ o preconceito destaca os componentes essenciais que encontramos em todos os tipos de atitudes" (LAMBERT; LAMBERT, 1972, p. 78).

Os psicólogos sociais entenderam que:

As atitudes desempenham papeis importantes na determinação de nosso comportamento. Por exemplo, influem em nossos juízos e percepção dos outros; 
influem na rapidez e eficiência de nossa aprendizagem, ajudam a determinar grupos a que nos ligamos, as profissões que finalmente escolhemos e até a filosofia que aceitamos (LAMBERT, 1975, p. 107).

Os julgamentos que as pessoas fazem sobre o falar dos outros mostram, na realidade, a percepção que possuem sobre elas mesmas, pois, ao ser julgado, o que fica em evidência não é apenas o sotaque, os dialetos, ou gírias que falam, mas a própria identidade, algo tão particular que envolve as crenças linguísticas.

As atitudes linguísticas diante do falar do outro reitera o próprio falar de quem julga ou marca o falar do outro como algo que se deseja ou rechaça, definindo a perspectiva do discurso público sobre a língua, o qual é carregado de avaliações e julgamentos de distinta natureza (GIMENES; MENDES NUNES, 2014, p. 164).

Logo, as atitudes em relação à língua estão condicionadas, também, ao grupo em que a pessoa participa e cria vínculos. Assim, as convicções desse grupo podem trazer julgamentos em relação a grupos distintos que não compartilham da mesma ideologia ou linguajar, que configuram as comunidades de fala, definidas como "[...] noção que recobre tanto aspectos sociais quanto linguísticos, envolvendo atitudes/normas sociais compartilhadas pelos falantes que, por sua vez, compartilham características linguísticas que os diferem de outros grupos sociais" (COELHO, 2010, p. 163).

As crenças também são evidenciadas por Labov como "[...] um conjunto uniforme de atitudes frente à linguagem que são partilhados por quase todos os membros da comunidade de fala, seja no uso de uma forma estigmatizada ou prestigiada da língua em questão" (LABOV, 2008, p. 176).

Ele chegou à conclusão de que o julgamento negativo ou positivo diante da fala pode “influenciar no processo de adaptação, variação e mudança linguística, [...] no qual a conduta do falante é analisada de acordo com sentimentos e opiniões sobre sua própria variedade linguística e em relação a outras com as quais mantém contato" (SILVA-PORELI, 2010, p. 13). Os estudos brasileiros sobre atitudes linguísticas evidenciam que existem várias comunidades distintas que formam o falante com diferentes vocabulários no extenso território, cada um possui traços linguísticos de sua região, sotaques que norteiam os vários falares que cada comunidade possui, ou adquire individualmente.

"A maioria das pessoas reconhece por sotaque a existência de falares distintos. Muitas atribuem a esse termo a noção de um conjunto de diferenças fonéticofonológicas, prosódicas e morfossintáticas dentro de uma mesma língua" (LIMA NETO, 2018, p. 47). As diferentes formas de pronunciar uma palavra acabam por denunciar à qual região uma pessoa pertence. Essas diferentes formas de falar evidenciam não só sotaque de uma pessoa, mas as influências linguísticas que ela recebe, o que marca a não existência de um falar homogêneo nas regiões 
brasileiras.

\subsection{Os estudos sociolinguísticos sobre as atitudes linguísticas no Brasil}

Existe um vasto campo a ser pesquisado no Brasil sobre as atitudes linguísticas, pois cada lugar possui contatos linguísticos que estão relacionados à colonização e à migração pela qual passaram ao longo das influências recebidas.

Alves (1979) observou, em seu estudo sobre as atitudes linguísticas de nordestinos em São Paulo, que seus informantes avaliam positivamente o próprio falar, quando relacionado a pessoas bem-sucedidas profissional e financeiramente. Por outro lado, também averiguou uma supervalorização do falar paulista, o que se deve ao deslocamento de nordestinos para uma região que eles acreditam como uma oportunidade de melhoria de vida, que traz consigo a apropriação do falar desse nova região, razão pela qual o falar paulista se marca como um falar de prestígio, de oportunidade profissional e financeira. Alves entendeu como atitudes linguísticas:

[...] um processo, dotado de certas etapas, e não simplesmente como um resultado. Ou seja, a percepção do objeto e a demonstração ativa de um indivíduo, a partir dele e com relação a ele, são precedidas e reforçadas por outros procedimentos: o enquadramento do objeto no sistema de crenças e valores do indivíduo e sua eventual reação emotiva a ele. A tendência para um certo tipo de ação torna-se assim o produto, o resultado final desse confronto (ALVES, 1979, p.27).

Essas atitudes ficaram evidenciadas ao constatar que os nordestinos buscavam a hipercorreção para que no falar pudesse assemelhar-se aos paulistas, disfarçando o seu sotaque, pois, na concepção deles, a fala de prestígio na cidade de São Paula não seria a deles.

Bisinoto (2000), em sua pesquisa sobre os efeitos migratórios no município de Cáceres - MT, abordou dois questionários, um para imigrantes, outro para os nativos de Cáceres, constatando que tanto os imigrantes quanto os cacerenses desprestigiam o falar local, o que assinala o risco de extinção do falar típico de Cáceres, algo preocupante, pois o preconceito sobre o falar "feio" e de desprestígio se marca nas gerações mais novas do município.

Silva-Poreli (2010) verificou em sua pesquisa atitudes positivas em relação à variedade de falares presentes na cidade de Pranchita-PR, algo que pode estar relacionado à condição em que a pessoa está inserida, pois, ao responder o questionário, é possível que tenha havido um monitoramento acerca da fala, assim os nascidos neste município veem de maneira positiva as diferentes comunidades de fala no local. A pesquisadora pode constatar quatro atitudes positivas em Pranchita:

a) Apreço à língua dos seus ancestrais, sentimento de pertencimento relacionado à etnia, sem que, com isso, haja rejeição aos costumes e à língua brasileira; b) atitude 
de aceitação, sem maiores restrições à língua e à cultura do Brasil; c) atitude de "tentativa" de manter os valores e às línguas dos antepassados; e d) atitudes muito positivas em relação ao país vizinho, Argentina, e ao seu idioma (SILVA-PORELI, 2010, p. 100).

Silva (2016) também abordou o mesmo tema na região de Cáceres-MT, com a dissertação Contatos Bilíngues: Atitudes Linguísticas da Interação do Falar Boliviano com o Falar Cacerense, para conhecer como veem o falar de cada um, que se apresentou de maneira positiva, mas de insegurança quanto à hipercorreção. A questão social ficou evidente, uma vez que há a presença de preconceito em relação a quem não estuda, fala errado, um julgamento que a Sociolinguística observa como estigmatizado, pois é uma abordagem social e de status sobre a língua falada, mas que não qualifica ou defini uma pessoa.

A dissertação de Dalleaste (2016) sobre as crenças e as atitudes linguísticas que envolvem a língua e a cultura italiana dos italodescendentes residentes na cidade de MatelândiaPR constatou que a língua italiana é mais falada entre as pessoas de mais idades e que esta língua tem valor sentimental, já que, para os mais novos, ela quase não está presente, mesmo em momentos de descontração entre os amigos. A pesquisadora registrou que a língua italiana tem caído em esquecimento, pois as crenças e as atitudes existentes na cidade não são suficientes para que seja incentivado o estudo e aprendizagem entre os falantes de língua portuguesa da região, embora haja o valor linguístico dela.

Por fim, a dissertação A aldeia lagoinha e suas atitudes linguísticas frente ao bilinguísmo entre as línguas terena e portuguesa numa perspectiva sociolinguística, de Rodnei Eloi Silva (2019), mostrou a preocupação em manter a língua terena viva, pois até entre os índios terenas as variações linguísticas têm tomado proporções onde a língua nativa está sendo desvalorizada, sobretudo entre os mais novos, por ser uma língua minoritária, de modo que a língua portuguesa é a mais prestigiada.

\section{Metodologia da pesquisa}

O corpus da pesquisa é constituído por um questionário que é, segundo Gil, "[...] o meio mais rápido e barato de obtenção de informações, além de não exigir treinamento de pessoal e garantir o anonimato" (GIL, 2002, p. 115). Ainda segundo o autor: "Porquestionário entende-se um conjunto de questões que são respondidas por escrito pelo pesquisado". (Gil, 2002).

As considerações de Manzini (2003) também foram mobilizadas no que tange à entrevista semiestruturada, seguindo um roteiro previamente elaborado para que os objetivos fossem alcançados, a fim de que houvesse sucesso na coleta de dados para análises das 
respostas.

A pesquisa não ocorreu in loco devido ao distanciamento social promovido pelo vírus Covid 19, assim, o aplicativo WhatsApp serviu de maneira rápida e satisfatória para que esta pesquisa tivesse sucesso.

O questionário abordou 13 perguntas visando responder aos objetivos elencados neste estudo, três delas apresentaram as seguintes opções como alternativas: Paulista, Mineira, Sulista, Goiana, Costarriquense e Alagoana, para que fosse possível constatar o prestígio que estes falares representam para os costarriquenses.

\subsection{Os informantes}

Foram selecionados 20 informantes, entre eles 10 homens e 10 mulheres, grau de escolaridade ensino básico e superior, diageracional (20 e 57 anos de idade), que nasceram no município de Costa Rica - MS.

Tabela 1 - Os informantes.

\begin{tabular}{|c|c|c|c|c|c|c|}
\hline & $\begin{array}{c}\text { Sexo Masculino } \\
\text { Profissão }\end{array}$ & $\begin{array}{c}\text { Nível de } \\
\text { Escolaridade }\end{array}$ & Idade & $\begin{array}{c}\text { Sexo Feminino } \\
\text { Profissão }\end{array}$ & $\begin{array}{c}\text { Nível de } \\
\text { Escolaridade }\end{array}$ & Idade \\
\hline Informante 1 & Advogado & Ensino Superior & 23 & Recepcionista & Ensino Básico & 20 \\
\hline Informante 2 & Téc. Agrícola & Ensino Básico & 24 & FuncionáriaPública & EnsinoSuperior & 28 \\
\hline Informante 3 & Pedreiro & Ensino Básico & 28 & Manicure & Ensino Básico & 29 \\
\hline Informante 4 & Servidor Público & Ensino Superior & 31 & GerenteFinanceiro & EnsinoSuperior & 32 \\
\hline Informante 5 & Técnico em RH & Ensino Superior & 38 & Vendedora & Ensino Básico & 36 \\
\hline Informante 6 & Fisioterapeuta & Ensino Superior & 39 & Dentista & EnsinoSuperior & 40 \\
\hline Informante 7 & Radialista & Ensino Básico & 41 & $\begin{array}{c}\text { Caixa de } \\
\text { Supermercado }\end{array}$ & Ensino Básico & 42 \\
\hline Informante 8 & Coord. Executivo & Ensino Básico & 45 & Professora & EnsinoSuperior & 46 \\
\hline Informante 9 & Tratorista & Ensino Básico & 55 & Comerciante & Ensino Básico & 52 \\
\hline Informante 10 & Professor & Ensino Superior & 64 & Advogada & EnsinoSuperior & 57 \\
\hline
\end{tabular}

Fonte: A autora (2020)

\section{Análise dos dados}

A análise dos dados seguiu as diretrizes abordadas neste estudo sobre as concepções de Labov acerca das atitudes linguísticas representadas em gráficos para exposição e explanação dos resultados, além da abordagem qualitativa para tratar das percepções que os falantes 
possuem sobre sua fala e sobre a dos outros.

A primeira questão: Qual língua você fala?

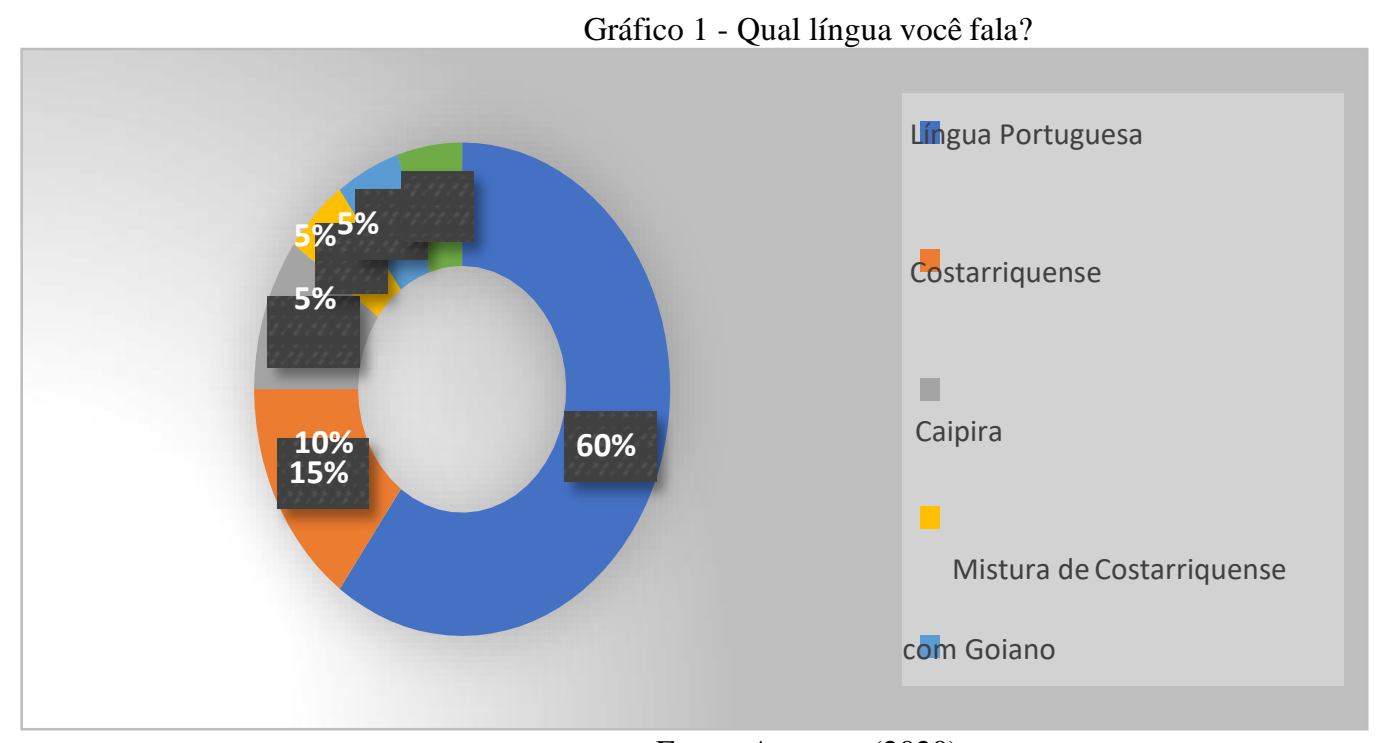

Fonte: A autora (2020)

Era esperada a resposta escolhida pela maioria dos entrevistados ser a Língua Portuguesa, pois é a predominante no Brasil, ensinada na escola como língua padrão, porém a variedade de resposta mostra a visão plural que as pessoas têm de como falam. As atitudes linguísticas culturais estão presentes na respostas Caipira, Mistura de Costarriquense com Goiano e Sul-Mato-Grossense.

A atitude não é meramente um resultado, mas um processo, envolvendo um complexo sistema de crenças, juízos de valor, emoções, reações e comportamentos. A tendência para certo tipo de ação se torna, nessa perspectiva, o produto, o resultado final desse confronto: é o momento em que as crenças e os valores afetivos se transformam em intenções comportamentais. (CORBARI, 2013, p. 238).

A identidade registrada na fala dos costarriquenses é de que o sotaque caipira, com o "r" retroflexo e o "s" puxado, é característico do falar sertanejo devido ao grande número de pessoas residentes no campo, os imigrantes vindos de Goiás, que possuem uma cultura muito forte de mineiros, contribuem para essa familiaridade de sotaque e costumes. Calvet mostra o perigo de perder a identidade do falar camponês: “em situações nas quais a urbanização é vivida como um perigo para a identidade, vai-se ao contrário valorizar o modo de falar dos camponeses, como mais próximo da língua “verdadeira” (CALVET, 2002, p. 75).

Com o crescimento da cidade, atualmente, há mais residentes urbanos do que rurais, visto que, há trinta anos, a população era maior no campo, informação segundo percepção de um dos entrevistados. Esta é a visão dos costarriquenses que têm mais de 30 anos, pois os mais novos não demonstraram ter essa mesma percepção em relação ao sotaque, muitos nem acreditam possuírem sotaque. O mesmo fenômeno foi estudado por Lima Neto (2018), o qual 
observou que, na percepção dos brasilienses, eles também não possuem sotaque, logo o aspecto diageracional fica evidente entre as gerações (43 e 60 anos e 23 e 32 anos), posto que pessoas nascidas e residentes no Plano Piloto e no Gama possuem atitudes linguísticas diferentes.

A segunda questão: Qual falar você acha mais bonito?

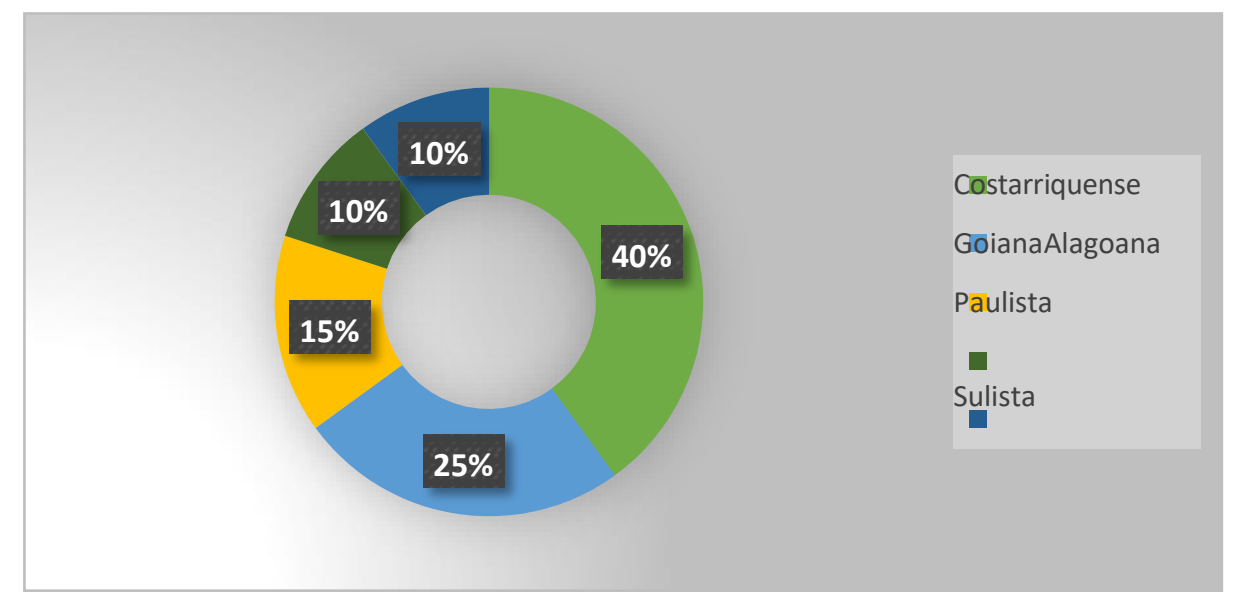

Gráfico 2 - Qual falar você acha mais bonito?

Fonte: A autora (2020)

O prestígio está registrado em $40 \%$ dos entrevistados, os quais consideram que o falar dos costarriquenses é o mais bonito, logo, não possuem vergonha da maneira como falam ou do linguajar que se expressam. Isso demonstra aceitação e familiaridade com o próprio modo de falar, mostrando também favorecimento às suas origens e bagagem cultural adquirida com as variações que este falar sofreu ao longo do tempo. Calvet explica que a segurança linguística acontece: “[...] quando, por razões sociais variadas, os falantes não se sentem questionados em seu modo de falar, quando consideram sua norma a norma" (CALVET, 2002, p. 72).

O segundo registro remete ao fato de que, em vários momentos na entrevista, muitos apontaram as influências goianas tanto no sotaque quanto na cultura costarriquense, talvez seja essa a justificativa de ter esta língua um porcentual mais elevado do que as demais alagoana, paulista e sulista.

Não era esperado que o falar sulista ocupasse a última colocação, pois, na região, há muitos sulistas e a cultura e o linguajar deles estão misturados ao sotaque local. Um entrevistado destacou: “Antigamente a gente não ouvia ninguém chamar um moleque de guri, mas agora sim, porque os gaúchos vieram para cá e eles falam, nós nos acostumamos a falar também." E ainda que, segundo os informantes, o falar sulista é o segundo considerado o mais correto.

A questão 3: Qual falar você acha mais feio? 
Gráfico 3 - Qual falar você acha mais feio?

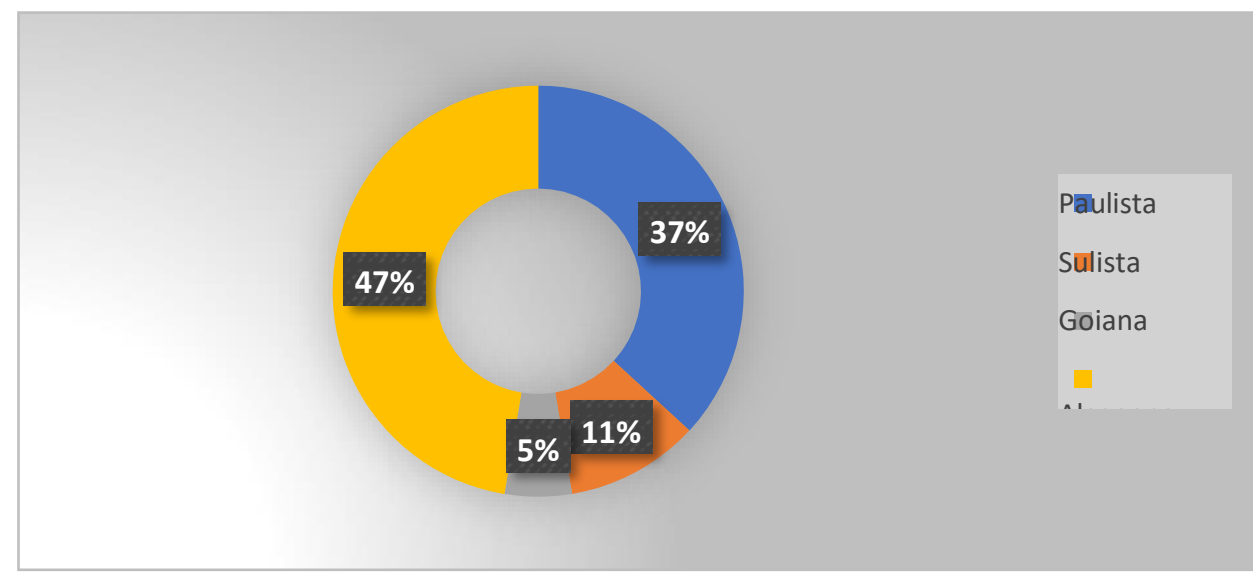

Fonte: A autora (2020)

Provavelmente a escolha de menor prestígio seja o falar alagoano, pois os alagoanos, entre todas as opções, são os últimos imigrantes que migraram para Costa Rica devido à oportunidade de emprego oferecida pela Usina Atvos, fato que pode gerar estranheza para os costarriquenses, visto que são culturas e sotaques bem diferentes. O que se pode perceber em relação aos alagoanos é que a cidade cresceu muito em virtude da chegada deles, mas, com isso, alguns fatos foram negativos, conforme um entrevistado:

Inf.: eles (os alagoanos) ganham dinheiro aqui, mas não gastam aqui, mandam para a cidade deles. A saúde e o impacto em outras áreas também são perceptíveis como o valor do aluguel, como aumentou a demanda, o aluguel também aumentou muito, mas o salário de nós que já morávamos aqui não melhorou nada.

Segundo os PCNs, “[...] há muitos preconceitos decorrentes do valor social relativo que é atribuído aos diferentes modos de falar: é comum se considerarem as variedades de menor prestígio como inferiores ou erradas" (BRASIL, 1997, p. 171). Porém, esse valor de prestígio não é determinante no conteúdo identitário dos alagoanos ou de qualquer outro imigrante. Embora a comunidade de fala deles seja minoritária, o respeito e o valor devem servir para acolhimento e interação com a região.

Bourdieu percebeu que esse desprestígio em relação ao falar do outro pode ser uma questão linguística e social, pois, na realidade, a língua não é estigmatizada, mas está relacionada diretamente com o falante, e envolve questões mais complexas do que a língua, como as classes sociais (CALVET, 2002).

Questão 4: Qual fala é a mais correta? 
Gráfico 4 - Qual fala é a mais correta?

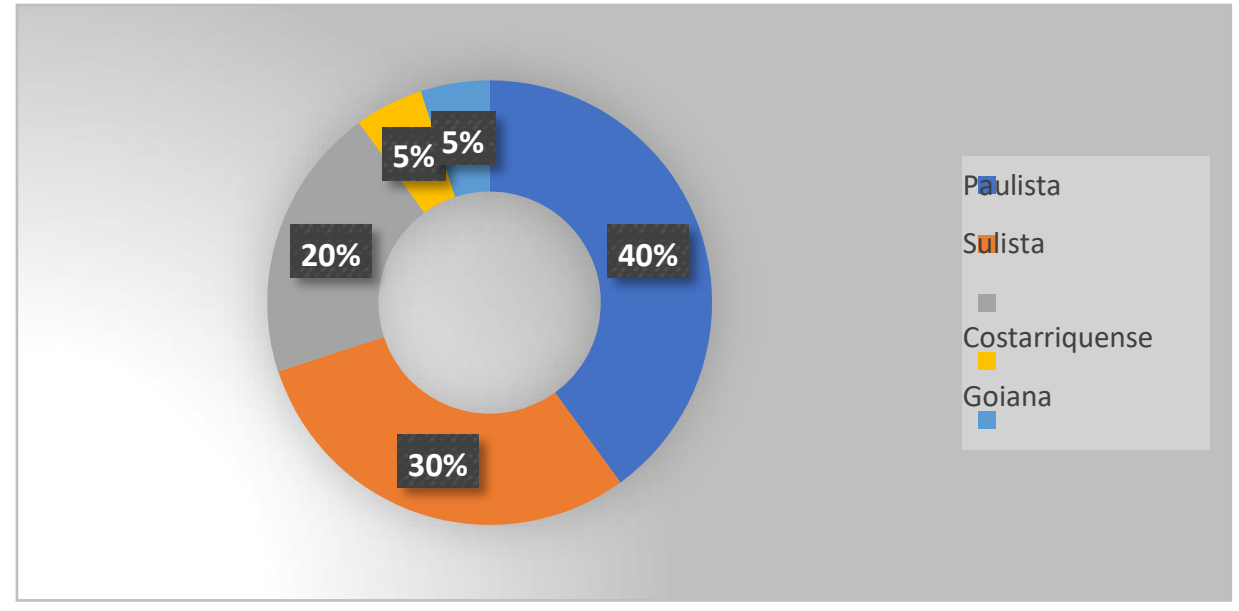

Fonte: A autora (2020)

O falar paulista ganhou destaque, já que $40 \%$ dos entrevistados o consideram o mais correto. Calvet, ao descrever a pesquisa de Labov em Nova York, destacou que “[...] os falantes consideravam como marca de prestígio algumas formas de pronúncia que eles mesmos não praticavam" (CALVET, 2002, p. 72). Este fato está registrado na fala dos costarriquenses, em que os hábitos culturais têm mais semelhança do que o sotaque paulista. Com 30\% das respostas voltadas para o modo de falar sulista, o léxico desta região está presente no falar dos costarriquenses, tornando mais rico e singular o vocabulário que estes informantes possuem. $\mathrm{O}$ falar costarriquense ocupa a terceira posição, o que demonstra que, embora haja muitas culturas importantes na região, este falar ainda é visto como um dos mais corretos.

Lambert e Lambert (1972) pontuam que as atitudes linguísticas também estão relacionadas à personalidade, ao modo como o sujeito reage às relações com os diversos grupos sociais e ocupacionais, "são traços da personalidade" (LAMBERT; LAMBERT, 1972, p. 91). Entende-se, então, que, embora o falar costarriquense seja explicado por eles mesmos como caipira ou sertanejo, os nativos o consideram correto, pois, ao falar com o "r" retroflexo, por exemplo, marca-se uma atitude de sua personalidade, construída, principalmente, no meio familiar, sem a preocupação com a norma culta, que, aparentemente, possa estar envolvida na maneira dos paulistas e dos sulistas falarem.

A questão 5: O que as pessoas de outros estados falam de diferente de você?

A Sociolinguística apresenta a língua como fenômeno variável e que as variedades linguísticas estão relacionadas a fatores geográficos, visando como cada região apresenta as suas atitudes e crenças linguísticas. As diversas respostas mostram essa variação: 
o que ela falava, um exemplo é bora, bora.

Inf.: Uai, Oxente, vici, acumé.

Inf.: Alternância de algumas letras, sotaque e algumas coisas possuem nome diferentes ex: farda para os maranhenses e aqui uniforme, rancho para o sul e aqui compra.

Inf.: Por exemplo algumas palavras típicas de cada região, no sul as pessoas falam tchê, no estado de Goias falam uai.

Inf.: Bah, tu fizestes, macaxeira, painho, muié, dentre muitos outros exemplos que abrangem sotaque, conjugação correta dos verbos, palavras regionais...

Inf.: Cadinho, fisso, barrer, boutá

A maneira como um falante se expressa aponta, emocionalmente, a construção linguística da região em que nasceu, assim, a pluralidade da fala constrói-se de acordo com os contatos que a língua vai estabelecendo, amplia-se o vocabulário e estabelecem-se novas concepções acerca da variedade prestigiada.

As respostas assinalam a variedade de vocabulário presente na região, porém apresentam, na realidade, apenas as atitudes pelas quais as pessoas expõem o seu modo de ver a língua, posto que, conforme Monteiro: “[...] duas ou mais formas distintas de se transmitir um conteúdo informativo constituem, pois, uma variável linguística.” (MONTEIRO, 2008, p. 59)

\footnotetext{
A questão 6: O que você fala de diferente das pessoas dos outros estados?

Inf.: A expressão pior, aqui quer dizer: é verdade.

Inf.: Quando estou com pressa, eu falo que fiz alguma coisa no doze.

Inf:: $O$ som do $R$ mais forte, algumas coisas possuem nomes diferentes como mandioca - big bem, troca do e pelo i ex: tomati, leiti, redução de letra ex. Está por tá.

Inf.: Palavras como: sei lá, se que sabe...

Inf.: Leithi (leite), porrta (porta), você fez, mandioca, dentre muitos outros exemplos.

Inf.: Nóis vai passea. Eu sei o jeito certo de falar, mas eu falo igual todo mundo da minha família.

Inf.: Eu não sei se posso falar isso, mas aqui, a palavra cu tem muito uso, por exemplo, eu tomo cu de burro, outra coisa, é de cair o cu da bunda, não faz cu doce, não faz essa cara de cu. Muita gente fala essas coisa kkk, mais é assim.

Inf: Véio, oh loco, fiquei zuado, mano do céu, cê tá ligado.
}

Esta variação já mencionada por Labov tem representatividade na Sociolinguística, ao se perceber que os fenômenos das variações não mudam o comportamento do falante: "variação corresponde à concorrência de duas formas num mesmo contexto, apresentando o mesmo valor semântico" (SILVA, 2016, p. 22). Essas mudanças são entendidas como língua de contato, de modo que Calvet (2002) argumenta que toda língua empresta e influencia outra nos aspectos fonético, lexical e sintático.

A resposta do informante, Não vejo muita diferença, remete à questão do sotaque, já que ele mencionou acreditar que não possui sotaque, talvez pelo costume de ouvir sempre os mesmos grupos sociais, o que aparentemente incorreria na não percepção, por ele, de diferenças 
fonéticas.

É o que se trata nas questões 7 e 8: Você tem sotaque? Consegue descrever seu sotaque?

Gráfico 5 - Você tem sotaque? Consegue descrever seu sotaque?

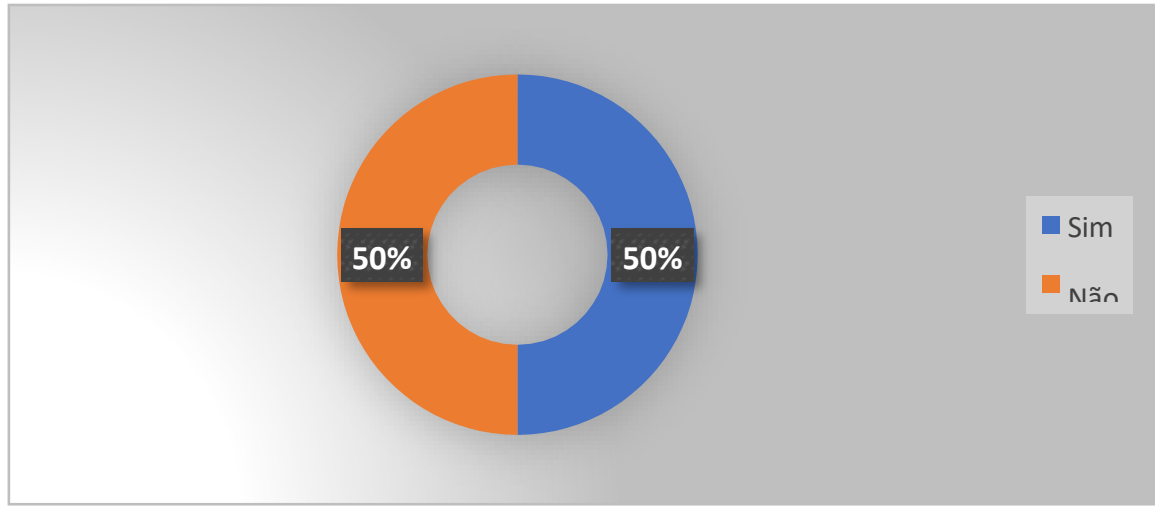

Fonte: A autora (2020)

Não puxamos muito o r e s. Esse informante não percebeu no seu falar o "r" retroflexo, já mencionado na primeira questão, que muitos costarriquenses consideram como uma pronúncia puxada. Outras justificativas são:

Inf.: Não sei seria sotaque mais o som do $R$ é mais forte que em outras regiões. Inf.: Eu não tenho sotaque.

Inf.: Eu falo igual todo mundo aqui, então eu não tenho sotaque.

Inf.: Acho que eu e minha família falamos as mesmas coisas, do mesmo jeito, sem sotaque.

Lima Neto (2018) também constatou que muitos brasilienses acreditam que existe uma mistura em seu sotaque, principalmente pela influência nordestina, assim como os seguintes costarriquenses:

Inf.: Uma mistura de goiano com mato-grossense, sei lá.

Inf.: Sotaque costarriquense.

A questão 9: Você acha que o sotaque dos costarriquenses é muito diferente dos imigrantes da região?

Ao abordar os aspectos regionais, os costarriquenses tiveram que refletir sobre as muitas comunidades linguísticas diferentes presentes no município. Embora 50\% dos informantes não acreditem possuir sotaque, $65 \%$ percebem que a maneira que eles falam é diferente do modo que os imigrantes falam. Houve uma divergência nesta informação, pois, ao se considerarem sem sotaque, seria pouco perceptível os diferentes falares que envolvem as identidades regionais. 
RELACult - Revista Latino-Americana de Estudos em Cultura e Sociedade

Revista Latinoamericana de Estudios en Cultura y Sociedad | Latin American Journal of Studies in Culture and Society V. 07, ed. especial, mar., 2021, artigo no 2120 | claec.org/relacult | e-ISSN: 2525-7870

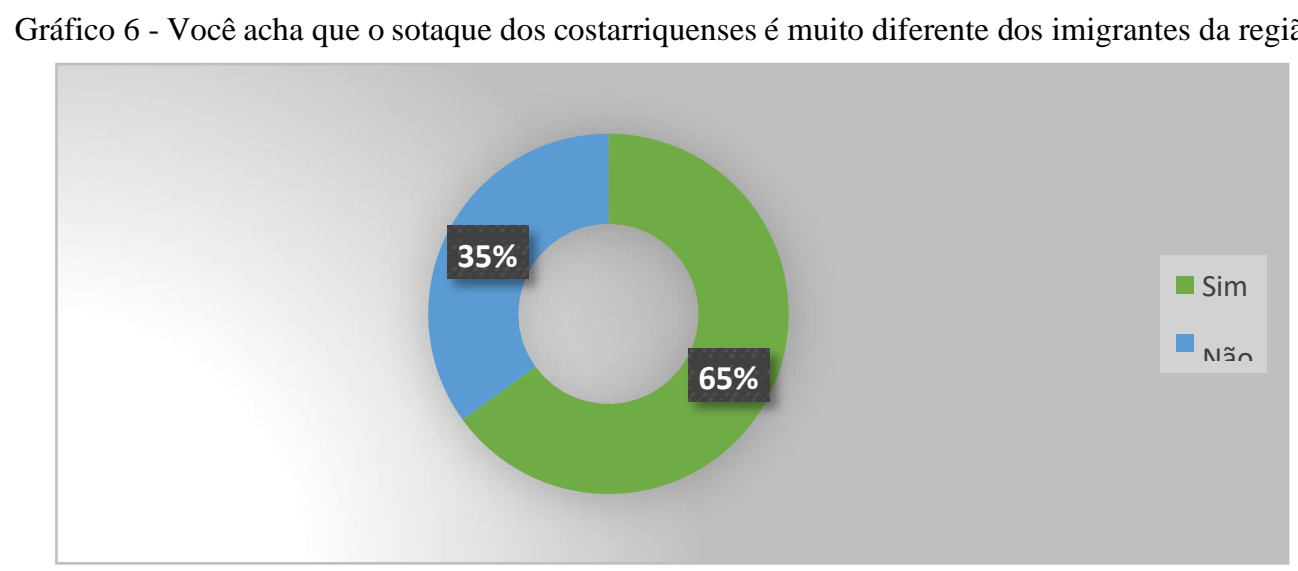

Fonte: A autora (2020)

A questão 10: Poderia explicar o porquê isso acontece?

O processo de migração está presente nas respostas em que os costarriquenses percebem que as várias influências de outras regiões estão inseridas nas atitudes e crenças linguísticas que eles aprenderam na convivência familiar e em outras situações.

Inf:: Devido ao fator linguístico, cada região tem o seu jeito de falar.

Inf:: Eu acho que a maioria fala tudo igual, um pouco de mato-grossense, mais um tanto de goiano e até mineiro, tudo misturado.

Inf:: Nós falamos como nossos familiares, meus pais são de Alagoas, eu nasci aqui, eu falo um pouco de cada, meus pais também falam parecido com o povo daqui.

Inf:: Nós temos influência de Goiás, de São Paulo e dos sulistas e usamos algumas expressões típicas do Paraguai e Bolivia.

Inf.: Aqui tem muitos gaúchos, a cultura deles é diferente, então eles falam diferente de nós.

Para Silva, "O contato entre línguas está associado a comportamentos e atitudes, os quais produzem diferentes efeitos sociais na interação entre os sujeitos falantes de uma determinada comunidade." (SILVA, 2016, p. 34). Portanto, o costarriquense consegue definir algumas percepções sobre a construção linguística que permeia a sua fala, com o contato com goianos, mineiros, sulistas, paraguaios e bolivianos que participaram da formação dialetal e que tem influenciado como as pessoas falam e vivem.

As questões 11 e 12: Você percebe que os costarriquenses de mais idade possuem uma maneira diferente de falar das gerações mais novas? Consegue descrever como eles falam?

Gráfico 7 - Você percebe que os costarriquenses de mais idade possuem uma maneira diferente de falar das gerações 
mais novas? Consegue descrever como eles falam?

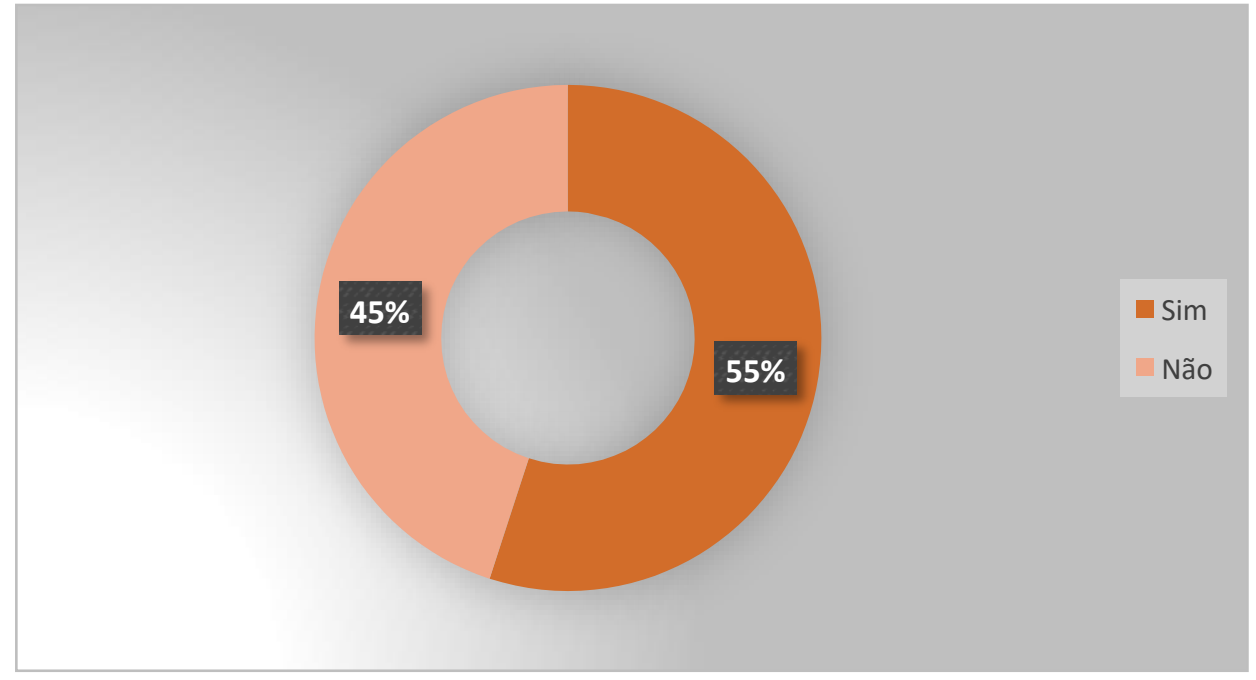

Fonte: A autora (2020)

A percepção dos informantes que possuem idade acima de 30 anos é bem evidenciada nestas respostas, ao se distinguir o próprio falar em relação ao falar dos migrantes. A idade foi um fator preponderante, como relata Bisinoto, que, ao escolher os informantes, priorizou os que tinham mais de 30 anos, já que "O limite etário é importante porque acreditamos que a atual geração de jovens e adolescentes já não sente tão fortemente o embate das forças sociais e da diversidade linguística como se observaram há algumas décadas. (BISINOTO, 2000, p, 51).
Inf.: Falam com muitos erros de concordância verbal e nominal.
Inf.: Eles falam bem calmos, igual ao meu avô, ele falava bem devagar.
Inf.: Tem algumas expressões da nossa família, que quando éramos crianças nós nem sabíamos o que significava. Por exemplo: minha mãe usava a palavra chamada sinapismo, outra expressão que a gente usava era purgante de jalapa e também ouvi meи pai falar estrovar, mas depois eu cresci e entendi que era estorvo.

Monteiro, em seus estudos, relata que algumas expressões não são citadas pelos informantes, como estrovar, palavra dificilmente pronunciada pelos mais jovens, e, talvez com risco de julgamentos, por idosos costarriquenses, que modificaram um pouco o seu vocabulário, ampliando-o e absorvendo as atitudes linguísticas dos imigrantes, além do contato com as novas gerações.

A própria língua como sistema acompanha de perto a evolução da sociedade e reflete de certo modo os padrões de comportamento, que variam em função do tempo e do espaço. Assim se explica os fenômenos de diversidade e até mesmo de mudança linguística. (MONTEIRO, 2008, p. 16)

Inf.: Acho que eles falam igual a todos os outros, independente de idade. Inf.: Não percebo diferença.

A questão 13: Já sentiu vergonha da sua maneira de falar? Explique. 
Gráfico 8 - Já sentiu vergonha da sua maneira de falar?Explique.

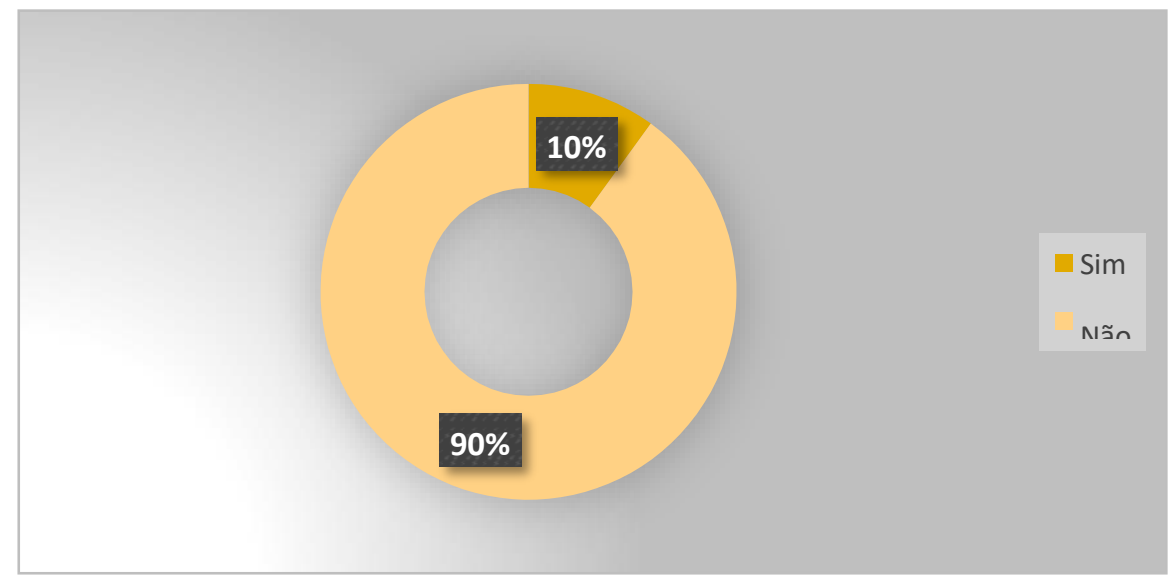

Fonte: A autora (2020)

Inf.: Eu já sim, quando fui para a praia, as pessoas riam de mim, achavam engraçado porque еи рихо о $r$.

Inf.: Nos mudamos para outro estado, moramos lá dois anos, meus colegas da escola debochavam porque o meu r era diferente do r deles, aí eu ficava com muita vergonha de falar.

Inf.: Eu não, acho bacana o meu sotaque, sotaque de sul mato-grossense. Inf.: Gosto muito do jeito que eu falo.

Inf.: Vergonha não, mas quando eu fui estudar em Uberlândia, as pessoas observavam que eu falava igual sertanejo.

Inf.: Eu nunca tive vergonha do meu jeito de falar, mas é lógico que as pessoas já debocharam do meu jeito sul-mato-grossense de falar.

O fato de $90 \%$ dos informantes registrarem que nunca sentiram vergonha do modo como falam, ou do seu próprio sotaque, afirma a identidade costarriquense como prestigiosa, situação em que é importante apontar a grande diversidade da língua portuguesa falada em todo território nacional, mas também a identidade de cada região e, no caso costarriquense: um sotaque misturado.

\section{Conclusões}

Embora ainda exista um campo muito grande a ser explorado na região de Costa Rica sobre as atitudes linguísticas, este trabalho mapeou que os costarriquenses possuem orgulho da maneira que falam e não encontram preconceito nos falares que envolvem as influências dos imigrantes. A fala de prestígio é a deles e descrevem este falar como caipira, de modo simples, semelhante ao sertanejo. O sotaque do costarriquense pode ser descrito com o " $r$ " retroflexo, semelhante ao pronunciado pelos mineiros, que têm um "s" puxado, porém uma fala mais calma. Por outro lado, o falar que consideram mais correto, semelhante à norma culta de prestígio, não é o costarriquense, mas o paulista, seguido do sulista e em terceiro lugar o costarriquense, visto com maior prestígio que o falar alagoano. 
O fato de Costa Rica se localizar na fronteira entre os Estados de Mato Grosso e Goiás contribuiu para a construção das atitudes linguísticas de nossos informantes, em razão das influências culturais e do modo de viver dos habitantes que vieram desses estados, o que não é visto como algo negativo, mas relevante, além da importância das outras regiões citadas neste trabalho.

\section{Referências}

ALVES, M. I. P. M. Atitudes linguísticas de nordestinos em São Paulo: uma abordagem prévia. 1979. 226f. Dissertação (Mestrado em Linguística), Instituto de Estudos da Linguagem, Universidade Estadual de Campinas, Campinas, 1979.

BISINOTO, L. S. J. Atitudes sociolingüisticas em Cáceres-MT: efeitos do processo migratório. Campinas, SP: [s.n.], 2000.

BRASIL. Secretaria de educação fundamental. Parâmetros Curriculares Nacionais: língua portuguesa-ensino de $1^{\text {a }}$ a $4^{\mathrm{a}}$ série. Brasília: MEC / SEF, 1997.

CALVET, L-J. Sociolinguística: uma introdução crítica. Tradução Marcos Marcionilo. São Paulo: Parábola, 2002.

COELHO et al. Sociolinguística. Florianópolis: LLV/CCE/UFSC, 2010. Disponível em: http://ppglin.posgrad.ufsc.br/files/2013/04/Sociolingu\%C3\%ADstica_UFSC.pdf. Acesso em: 30 abr. 2020.

CORBARI, C. C. Atitudes Linguísticas: um estudo nas localidades paraenses de Irati e Santo Antônio do Sudoeste. Tese (Doutorado em Letras), Universidade Federal da Bahia, Instituto de Letras Programa de Pós-Graduação em Letras e Linguística, Salvador, 2013.

DALLEASTE, A. P. Crenças e atitudes linguísticas: um estudo da língua e cultura italianas em Matelândia/PR. Cascavel, 2016.

GIL, A. C. Como elaborar projetos de pesquisa. 4. ed. São Paulo: Atlas, 2002. LABOV, W. Padrões sociolinguísticos. São Paulo: Parábola Editorial, 2008.

GIMENES, G.S.; NUNES-MENDES, A.N. B. As expressões "égua" e "mana" na linguagem do amapaense. In: DALLA PRIA et. al.(orgs). Linguagem e línguas: invariância e variação. Campinas-SP: Pontes, 2014.

LAMBERT, W. W.; LAMBERT, W. E. Psicologia social. 3. ed. Rio de Janeiro: Zahar, 1972.

LAMBERT, W. W. Psicologia Social. Trad. Dante Moreira Leite. 5. ed. Rio de Janeiro: Zahar, 1975.

LIMA NETO, N. V. Brasília, sua gente, seus sotaques: difusão candanga e focalização brasiliense na capital federal. 2018. 259 f., il. Dissertação (Mestrado em Linguística), Universidade de Brasília, Brasília, 2018.

MANZINI, E. J. Considerações sobre a elaboração de roteiro para entrevista semi-estruturada. 
In: MARQUEZINE: M. C.; ALMEIDA, M. A.; OMOTE; S. (Orgs.) Colóquios sobre pesquisa em Educação Especial. Londrina: Eduel, 2003. p.11-25.

MONTEIRO, J. L. Para compreender Labov. 3 ed. Petrópolis-RJ: Vozes, 2008.

OLIVEIRA, W. R. M. Atitudes linguísticas na fala dos costarriquenses. Traços deLinguagem, v. 4, n. 1, p. 38-49, 2020.

PASTORELLI, D. S. Crenças e atitudes linguísticas na cidade de Capanema: um estudo da relação do português com línguas em contato. 2010. Dissertação (Mestrado em Estudos da Linguagem) - Universidade Estadual de Londrina, Londrina, 2010.

SILVA, E. G. Contatos Bilíngues: atitudes linguísticas da interação do falar boliviano com o falar cacerense. Cáceres, 2016.

SILVA-PORELI, G. A. Crenças e atitudes linguísticas na cidade de Pranchita-PR: um estudo das relações do português com línguas em contato. Londrina, PR: UEL, 2010.

SILVA, R. E. A aldeia Lagoinha e suas atitudes linguísticas frente ao bilinguismo entre as línguas Terena e portuguesa numa perspectiva sociolinguística. Campo Grande, MS: UEMS, 2019.

TARALLO, Fernando. A pesquisa sociolinguística. São Paulo: Ática, 1985. 